\title{
Kaolin dust concentrations and pneumoconiosis at a kaolin mine
}

\author{
EB ALTEKRUSE, BA CHAUDHARY, MG PEARSON, WKC MORGAN \\ From the Department of Medicine and Family Practice, Medical College of Georgia, Augusta, Georgia, USA, \\ and the Department of Medicine, University of Western Ontario, London, Ontario, Canada
}

ABSTRACT Kaolin is removed from underground seams in the mining area to a processing area, where it is sliced, dried, and pulverised to make the finished product. A study was undertaken to determine the dust concentrations in various work areas and to assess the prevalence of radiographic and pulmonary function abnormalities in 65 workers at a Georgia kaolin mine. Respirable dust concentrations were higher in the processing area than in the mine or maintenance areas for all determinations from 1977 to 1981 . The mean respirable dust level in the processing area in 1981 was $1.74 \mathrm{mg} / \mathrm{m}^{3}$ and $0.14 \mathrm{mg} / \mathrm{m}^{3}$ in the mine area. Five workers, all of whom had worked at the processing area, had radiographic evidence of kaolin pneumoconiosis. The mean values of forced vital capacity (FVC) and $\mathrm{FEV}_{1}$ of the entire group were within the normal range. When the spirometric values were expressed as a percentage of the predicted values, the FVC and $\mathrm{FEV}_{1}$ were significantly lower in the workers with kaolinosis than in other workers in the processing area. The FVC and $\mathrm{FEV}_{1}$ also declined significantly with increasing years of work in the processing area. The $\mathrm{FEV}_{1} / \mathrm{FVC} \%$, however, was not significantly altered either by the presence of kaolinosis or by an increasing number of years of work, indicating that the impairment was restrictive and hence likely to be a consequence of dust inhalation rather than smoking. In this study the highest dust concentrations occurred in the processing area, and kaolin pneumoconiosis was limited to those who had worked there. Kaolin exposure appeared to have a small but significant effect on ventilatory capacity in those with kaolin pneumoconiosis and in workers with a longer exposure. There was no association between the radiographic appearances of kaolinosis and cigarette smoking or between the presence of radiographic abnormalities and reduced arterial blood gas tensions.

Kaolin or china clay is a hydrated aluminium silicate $\left(\mathrm{Al}_{2} \mathrm{O}_{3}, 2 \mathrm{SiO}_{2} 2 \mathrm{H}_{2} \mathrm{O}\right)$. China clay is an altered product of granite and deposits usually consist of a soft aggregation of sand, mica, and kaolinite, the latter in the form of microscopic plate like crystals consisting of aluminium silicate. The term clay does not refer to any precise chemical composition and kaolin may contain other constituents, such as silicon, iron, titanium, calcium, magnesium, copper, and sulphur. In Georgia kaolin is found in remarkably pure sedimentary deposits.

\footnotetext{
Address for reprint requests: Dr WKC Morgan, Chest Disease Service, University Hospital, Box 5339 Postal Station A, London, Ontario, Canada N6A 5A5.
}

Accepted 27 January 1984
Middleton described lung disease in china clay workers in 1936.' Since then other investigators have described both radiological and pathological changes occurring secondary to kaolin exposure..$^{2-7}$ In these studies kaolin dust concentrations were not determined, and hence no information is available about whether the dust exposure was the same in the mining and processing areas. Furthermore, detailed studies of pulmonary function have not been reported in subjects with kaolin pneumoconiosis. This study was conducted to determine (a) kaolin dust concentrations in the various areas of kaolin production; (b) the relationship of kaolin pneumoconiosis to dust exposure and work history; and $(c)$ the extent and type of any pulmonary impairment present in men with kaolin pneumoconiosis. 


\section{Methods}

The entire work force of 65 men employed at a kaolin mine in Georgia was studied. The records of present and past employment for each worker were obtained from the plant personnel office. The work sites were divided into the mining area, where kaolin was being removed from underground seams; the production and processing area, where the kaolin was being crushed and pulverised; and the plant and vehicle maintenance area. The kaolin, when it is removed from the underground seams, is in the form of moist lumps and there is very little visible dust generated during mining. The kaolin is taken from the mining area by trucks to a processing area, where refining takes place. Sand and other impurities are removed by filtering the clay through a fine mesh screen. The aqueous slurry is then centrifuged and the clay removed. Kaolin is processed by either a "wet" or a "dry" method (air flotation). In the wet method the kaolin is mixed with water and undergoes a series of operations to produce fine particle kaolin. In the dry method contact with water does not occur. The kaolin lumps are sliced, crushed, dried, and then stockpiled. The clay is further dried and pulverised by air flotation in various bins and mills. These processes lead to intense generation of dust. Dry processing was used extensively before 1940 but has been largely replaced by the wet method. Jobs in the production and processing area result in the highest exposure to dust; at this site kaolin lumps are pulverised, dried by air flotation, and then bagged and loaded into cars. Those who work in the processing area carry out all these jobs at different times, and are not solely baggers or pulverisers. Maintenance workers have intermittent exposure to dust when cleaning or repairing equipment but many had previously worked for a time in processing. The miners and those who work at or near the mine have virtually no exposure except when they walk through the processing area. Most new workers start in processing work, this being the least skilled; and while some move on to more skilled jobs such as maintenance, others remain in their original job. There were 17 workers at the mine area, 25 at the processing area, and 10 at the vehicle and plant maintenance area, some of whom had previously worked in the processing area. In addition, there were 13 workers in administrative positions located at or near either the processing area or the vehicle and plant maintenance area.

For qualitative analysis, two pounds of bulk samples were taken from the overburden, from kaolin lumps, and from intermediate and processed kaolin for analysis in the laboratories of the National Insti- tutes of Health. The bulk samples were also analysed by the United States Department of the Interior, Bureau of Mines, for mineral content and the presence of mineral fibres.

All personal air samples collected at this mine since 1977 from various areas were included in the study. They had been collected by the gravimetric dust sampling kit (MSA, Pittsburgh, Pennsylvania) containing a cyclone assembly with a preweighted cassette. The workers wore the sampling kit for eight hours; the cassettes were then analysed to determine time weighted averages. The free silica content of all respirable dust samples was determined by $x$ ray diffraction.

Each worker answered a modified Medical Research Council questionnaire about the presence of any symptoms, cigarette smoking, and place and duration of work. Standard posteroanterior and lateral chest radiographs were interpreted by two independent readers using the ILO 1980 classification. ${ }^{8}$ Spirometry was performed with a 7 litre waterless spirometer (Pulmonor, Jones Medical Instruments Company, Oak Brook, Illinois). The best forced vital capacity (FVC) and the best volume expired in the first second $\left(F E V_{1}\right)$ from three attempts were accepted as the subject's values. In those with radiographic evidence of pneumoconiosis flow-volume loops were performed (CPI, model 5300, Pulmo-Lab, Houston, Texas) and lung volumes were determined by body plethysmography (Auto-box, SRL Med Inc, Dayton, Ohio) according to standard methods. ${ }^{10}$ Arterial blood gas measurements were made at rest and after exercise.

The predicted values used for spirometry and flows were those of Morris et $^{\text {al }}{ }^{11}$ and for lung volumes those of Goldman and Becklake. ${ }^{12}$ Predicted values were corrected for black subjects by an adjustment factor of $0 \cdot 85 . .^{13}$

Dust concentrations from the different areas were compared with an unpaired Student's $t$ test. Spirometric comparisons between the subgroups were performed with the Wilcoxon rank sum test. A $p$ value of less than 0.05 was considered significant.

\section{Results}

The mineral analysis of the dust showed the composition to be $94-98 \%$ kaolinite and $2-6 \%$ anatare $\left(\mathrm{TiO}_{2}\right)$. Neither asbestiform fibres nor crystalline silica was detected in any of the respirable dust samples.

During a five year period (1977-81) 157 respirable dust measurements were obtained from the three main areas. The mean dust concentrations at the three areas and the number of samples analysed during the five year period are shown in figure 1 . 


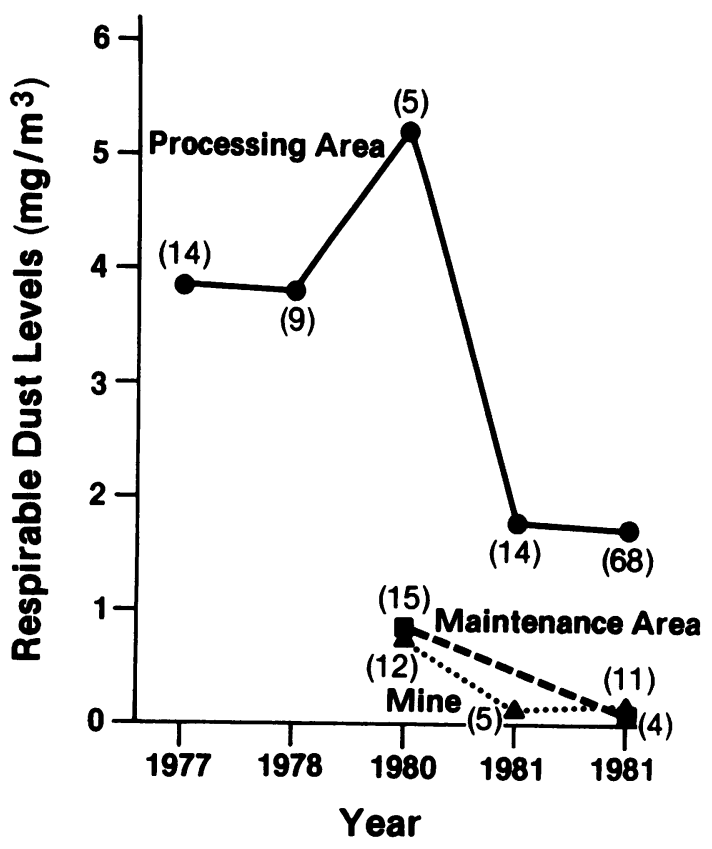

Fig 1 Dust levels from 1971 to 1981.

Throughout the study period the dust concentrations were significantly higher in the processing area than in the maintenance and mine areas ( $p<$ 0.025).

Radiographic abnormalities were found in five workers, all of whom worked in the processing area and all of whom had symptoms of bronchitis. One worker had complicated pneumoconiosis (fig 2) and four had simple pneumoconiosis. A summary of the radiographic findings appears in table 1 , with the time spent working in the processing shed. The radiographs of an additional four workers in the processing area were interpreted as category $0 / 1$. All had more than five years of exposure. In contrast, only one of the 40 radiographs of workers not employed in processing was interpreted as category $0 / 1$. The worker with complicated pneumoconiosis had spent his entire working life in the processing shed (36 years), while the worker with the shortest exposure (seven years) had the least radiographic abnormality.

The results of spirometry for all 65 workers and for subgroups based on working area are shown in table 2. The mean spirometric values were similar for all the subgroups. The individual results of spirometry and lung volume determinations of the five subjects with kaolin pneumoconiosis are shown in tables 3 and 4. The mean FVC and FEV, of these five, expressed as percentages of predicted values, were mildly but significantly reduced by compari-

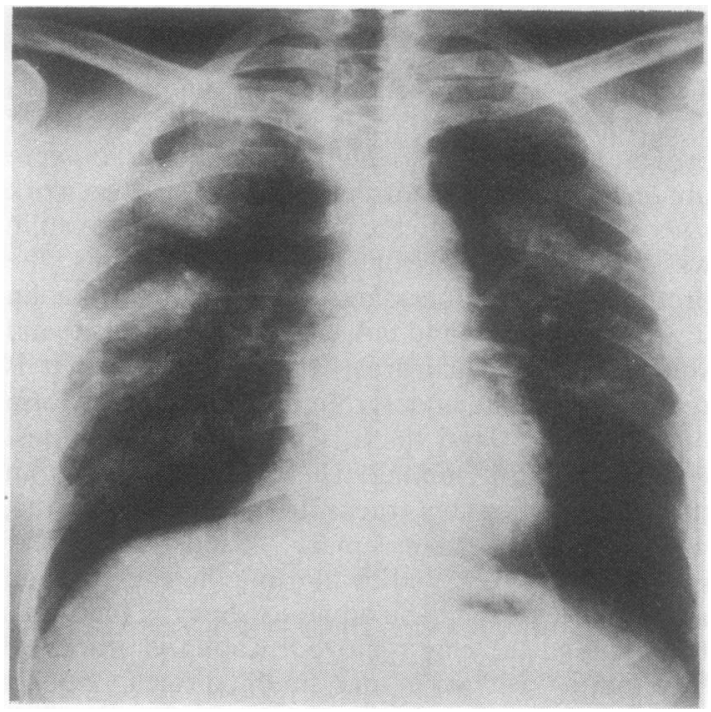

Fig 2 Radiograph of worker with complicated pneumoconiosis.

Table 1 Radiographic interpretations (ILO category ${ }^{8}$ ) of two observers $(A$ and $B)$ and the duration of work at the processing shed

\begin{tabular}{llll}
\hline Worker & $A$ & $B$ & Years \\
\hline 1 & C $2 / 2$ & C $2 / 2$ & 36 \\
2 & $2 / 3$ & $2 / 3$ & 11 \\
3 & $1 / 0$ & $0 / 1$ & 7 \\
4 & $1 / 2$ & $1 / 2$ & 13 \\
5 & $2 / 2$ & $2 / 2$ & 12 \\
\hline
\end{tabular}

sons with the means for the other 19 processing workers (table 5). One subject was excluded from this intragroup analysis since he had frank congestive cardiac failure at the time. Of the remaining $24 \gtreqless$ workers employed in processing, 12 had worked for 웅 less than five years in this area, seven had worked $\rightarrow$ for 5-10 years, and five for more than 10 years. The ventilatory capacity of the processing workers $N$ showed a small but significant decline in FVC with o increasing length of employment (fig 3 and table 5). 0 The $\mathrm{FEV}_{1}$ showed a similar small but significant trend $\left(\mathrm{FEV}_{1}=-0.72 \times\right.$ years worked $+102.3 ; \mathrm{r}=\mathrm{O}$ $0.45, \mathrm{p}<0.05)$. Although there were differences ${ }_{0}$ between the subgroups so far as smoking history and $\overparen{D}$ age were concerned (table 5), there was no ? significant difference in mean $F E V_{1} / F V C$. This sug- $\square$ gests that the mild impairment noted in those who had worked for longer periods was restrictive in character, and hence more likely to be due to dust $\mathbb{D}$

exposure than to smoking.
The results of the arterial blood gas analysis in the 
Kaolin dust concentrations and pneumoconiosis at a kaolin mine

Table 2 Mean spirometric values in kaolin workers according to work site

\begin{tabular}{|c|c|c|c|c|c|}
\hline Number & $\begin{array}{l}\text { Total } \\
65\end{array}$ & $\begin{array}{l}\text { Mine } \\
17\end{array}$ & $\begin{array}{l}\text { Processing shed } \\
25\end{array}$ & $\begin{array}{l}\text { Vehicle maintenance } \\
10\end{array}$ & $\begin{array}{l}\text { Others } \\
13\end{array}$ \\
\hline $\begin{array}{l}\text { FEV } \\
\text { SD } \\
\% \text { predicted }\end{array}$ & $\begin{array}{c}3.34 \\
0.78 \\
90.5\end{array}$ & $\begin{array}{l}3.03 \\
0.60 \\
92.8\end{array}$ & $\begin{array}{l}3.50 \\
0.90 \\
88.7\end{array}$ & $\begin{array}{l}3.26 \\
0.53 \\
85 \cdot 8\end{array}$ & $\begin{array}{l}3 \cdot 47 \\
0 \cdot 81 \\
94\end{array}$ \\
\hline $\begin{array}{l}\text { FVC (1) } \\
\text { SD } \\
\% \text { predicted }\end{array}$ & $\begin{array}{l}4.21 \\
0.88 \\
91.9\end{array}$ & $\begin{array}{l}3.90 \\
0.70 \\
90.4\end{array}$ & $\begin{array}{l}4.29 \\
1.03 \\
95 \cdot 5\end{array}$ & $\begin{array}{c}4 \cdot 24 \\
0 \cdot 83 \\
86 \cdot 4\end{array}$ & $\begin{array}{l}4 \cdot 45 \\
0 \cdot 79 \\
93\end{array}$ \\
\hline
\end{tabular}

Table 3 Spirometric values in workers with kaolin pneumoconiosis

\begin{tabular}{|c|c|c|c|c|c|c|}
\hline \multirow[t]{2}{*}{ Worker } & \multicolumn{2}{|l|}{$F V C$} & \multicolumn{2}{|l|}{$F E V_{1}$} & \multicolumn{2}{|c|}{$F E F_{25-75}$} \\
\hline & $l$ & $\%$ pred & $l$ & $\%$ pred & $l s^{-1}$ & $\%$ pred \\
\hline $\begin{array}{l}1 \\
2 \\
3 \\
4 \\
5 \\
5\end{array}$ & $\begin{array}{l}3 \cdot 14 \\
3.26 \\
3.24 \\
3 \cdot 60 \\
3.48\end{array}$ & $\begin{array}{l}82.4 \\
82.0 \\
82.6 \\
88.9 \\
81.0\end{array}$ & $\begin{array}{l}2 \cdot 20 \\
2 \cdot 53 \\
2 \cdot 58 \\
3 \cdot 14 \\
2 \cdot 88\end{array}$ & $\begin{array}{r}80.0 \\
85.0 \\
86.3 \\
100.6 \\
89.9\end{array}$ & $\begin{array}{l}2.45 \\
3.15 \\
3.43 \\
6.77 \\
4.35\end{array}$ & $\begin{array}{r}76.3 \\
99.4 \\
97.9 \\
171.8 \\
111.0\end{array}$ \\
\hline $\begin{array}{l}\text { Mean } \\
\text { SD }\end{array}$ & $\begin{array}{l}3 \cdot 34 \\
0 \cdot 19\end{array}$ & $\begin{array}{r}83 \cdot 4 \\
3 \cdot 1\end{array}$ & $\begin{array}{l}2.67 \\
0.39\end{array}$ & $\begin{array}{r}88.4 \\
7.7\end{array}$ & $\begin{array}{l}4.03 \\
1.69\end{array}$ & $\begin{array}{r}110.3 \\
36.6\end{array}$ \\
\hline
\end{tabular}

FVC_forced vital capacity; $\mathrm{FEF}_{2 \mathrm{~s}-7 \mathrm{~s}}$ forced expiratory flow-between points on the expiratory flow-volume curve where $25 \%$ and $75 \%$ of the vital capacity have been exhausted.

Table 4 Lung volumes in kaolin pneumoconiosis

\begin{tabular}{|c|c|c|c|c|c|c|c|}
\hline \multirow[t]{2}{*}{ Worker } & \multicolumn{2}{|l|}{$F R C$} & \multicolumn{2}{|l|}{$R V$} & \multicolumn{2}{|l|}{$T L C$} & \multirow{2}{*}{$\underset{(\%)}{R V / T L C}$} \\
\hline & $l$ & $\%$ pred & $l$ & $\%$ pred & $l$ & $\%$ pred & \\
\hline $\begin{array}{l}1 \\
2 \\
3 \\
4 \\
5\end{array}$ & $\begin{array}{l}3 \cdot 19 \\
3 \cdot 14 \\
3 \cdot 00 \\
2 \cdot 57 \\
2 \cdot 49\end{array}$ & $\begin{array}{r}88 \\
83 \\
107 \\
77 \\
69\end{array}$ & $\begin{array}{l}2.09 \\
1.74 \\
1.81 \\
1.13 \\
2.29\end{array}$ & $\begin{array}{r}95 \\
73 \\
94 \\
63 \\
111\end{array}$ & $\begin{array}{l}5 \cdot 23 \\
5 \cdot 00 \\
5 \cdot 05 \\
4 \cdot 73 \\
5.77\end{array}$ & $\begin{array}{l}82 \\
74 \\
81 \\
75 \\
83\end{array}$ & $\begin{array}{l}40 \\
35 \\
23 \\
24 \\
40\end{array}$ \\
\hline $\begin{array}{l}\text { Mean } \\
\text { SD }\end{array}$ & $\begin{array}{l}2 \cdot 88 \\
0.32\end{array}$ & $\begin{array}{l}84 \\
14 \cdot 9\end{array}$ & $\begin{array}{l}1.81 \\
0.45\end{array}$ & $\begin{array}{l}87 \cdot 2 \\
19.9\end{array}$ & $\begin{array}{l}5 \cdot 16 \\
0.39\end{array}$ & $\begin{array}{l}79 \\
4 \cdot 2\end{array}$ & $\begin{array}{r}32 \cdot 4 \\
8.4\end{array}$ \\
\hline
\end{tabular}

FRC—functional residual capacity; RV-residual volume; TLC_total lung capacity.

PREDICTEO

F V C

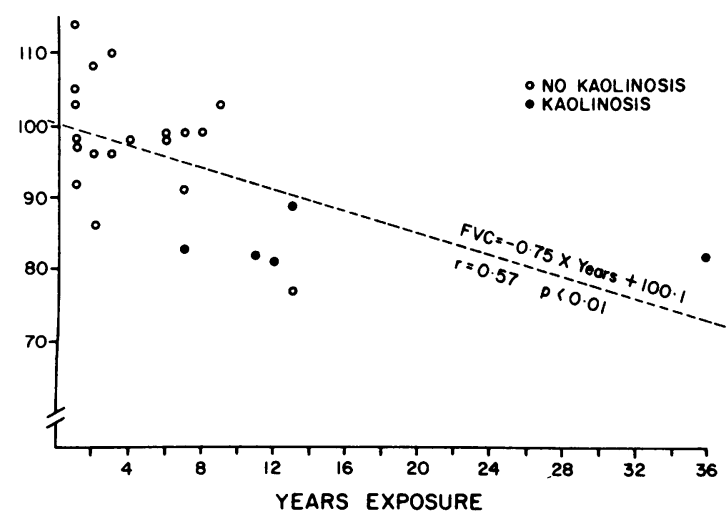

Fig 3 Relationship of forced vital capacity (FVC) to years of exposure in processing workers. five workers with kaolin pneumoconiosis are shown in table 6 . The mean alveolo-arterial oxygen tension gradient was $24.0 \mathrm{~mm} \mathrm{Hg}(3.19 \mathrm{kPa})$ at rest and $28.2 \mathrm{~mm} \mathrm{Hg}(3.75 \mathrm{kPa})$ after exercise. In three workers there was deterioration in oxygen tension after exercise but improvement was noted in the other two workers. There was no correlation between the severity of radiographic abnormality and either the degree of hypoxaemia at rest or the effect of exercise on oxygen saturation.

\section{Discussion}

Kaolin is not universally accepted as being capable of inducing pneumoconiosis. ${ }^{14}$ Our data, however, show, firstly, that kaolin pneumoconiosis is most likely to develop in workers in the processing area, where the dust levels are highest, and, secondly, that kaolin pneumoconiosis is associated with only mild 
Table 5 Comparison of workers with pneumoconiosis and their fellow processing area workers (means with one standard deviation)

\begin{tabular}{|c|c|c|c|}
\hline \multirow[b]{2}{*}{ Number } & \multirow{2}{*}{$\begin{array}{l}\text { With pneumoconiosis } \\
5\end{array}$} & \multicolumn{2}{|c|}{ Without pneumoconiosis } \\
\hline & & $>5 y$ work & ${ }_{12}^{<5}$ y work \\
\hline $\begin{array}{l}\text { Age } \\
\text { Smoking: pack years } \\
\text { FVC (l) } \\
\% \text { predicted FVC } \\
\text { FEV }(1) \\
\% \text { predicted FEV } \\
\text { FEV /FVC \% }\end{array}$ & $\begin{array}{l}47 \cdot 2(10 \cdot 0) \\
15 \cdot 8(4 \cdot 3) \\
3 \cdot 34(0 \cdot 19) \\
83 \cdot 4(3 \cdot 1) \\
2 \cdot 67(0 \cdot 39) \\
88 \cdot 4(7 \cdot 7) \\
80 \cdot 0\end{array}$ & $\begin{array}{c}37.5(11 \cdot 2)^{* *} \\
16 \cdot 1(10 \cdot 2) \\
4 \cdot 15(0 \cdot 39)^{* *} \\
95 \cdot 0(6 \cdot 8)^{* *} \\
3 \cdot 54(0 \cdot 42)^{* *} \\
102.2(11 \cdot 7)^{*} \\
85.3\end{array}$ & $\begin{array}{c}26 \cdot 9(9 \cdot 0)^{* *} \\
9 \cdot 8(9 \cdot 7) \\
5 \cdot 00(0 \cdot 82)^{* *} \\
100 \cdot 3(8 \cdot 80)^{* *} \\
4 \cdot 19(0 \cdot 86)^{* *} \\
100 \cdot 1(12 \cdot 6)^{*} \\
83.8\end{array}$ \\
\hline
\end{tabular}

*Significantly different from pneumoconiosis (kaolinosis) group $(p<0.05)$.

**Significantly different from pneumoconiosis (kaolinosis) group $(\mathrm{p}<0 \cdot 01)$.

FVC-forced vital capacity.

effects on pulmonary function.

Possible contamination by other dusts is an important consideration since silica exposure has been reported in kaolin firebrick workers ${ }^{15}$; but the fact that the dust to which our men had been exposed was pure kaolin, with no free silica or asbestos, was well established by the multiple qualitative analyses of the dust. The complete absence of silica indicates that inhalation of kaolin alone can lead to pneumoconiosis.

It is clear that the highest respirable dust concentrations occur in the processing area. The subjects in the present study worked at a mine where kaolin is still processed by the dry method, and on completion of this process $50-80 \%$ of the particles are in the respirable range. The prevalence of kaolin pneumoconiosis and the respirable dust concentrations are likely to be lower in those mines where wet processing is in use.

Measurement of dust levels before 1977 had been irregular and infrequent, but an earlier survey of several kaolin plants in Georgia showed dust concentrations over a hundred million parts per cubic foot. ${ }^{16}$ Thus there is little doubt that before regular dust sampling began dust concentrations had been far higher. Recent legislation and regulations have

Table 6 Alveoloarterial oxygen gradient before exercise and after exercise in patiens with kaolin pneumoconiosis

\begin{tabular}{|c|c|c|}
\hline \multirow[t]{2}{*}{ Worker } & \multirow{2}{*}{$\frac{\text { Before }}{(m m \mathrm{Hg}(\mathrm{kPa}))}$} & \multirow{2}{*}{$\frac{\text { After }}{(\mathrm{mm} \mathrm{Hg}(\mathrm{kPa}))}$} \\
\hline & & \\
\hline $\begin{array}{l}1 \\
2 \\
3 \\
4 \\
5\end{array}$ & $\begin{array}{l}12(1 \cdot 60) \\
36(4 \cdot 79) \\
18(2 \cdot 39) \\
29(3 \cdot 86) \\
29(3 \cdot 86)\end{array}$ & $\begin{array}{r}29(3 \cdot 86) \\
25(3.33) \\
2(0 \cdot 27) \\
35(4.66) \\
50(6.65)\end{array}$ \\
\hline $\begin{array}{l}\text { Mean } \\
\text { SD }\end{array}$ & $\begin{array}{c}24(3 \cdot 19) \\
9 \cdot 6(1 \cdot 28)\end{array}$ & $\begin{array}{l}28.2(3.75) \\
17.5(2.33)\end{array}$ \\
\hline
\end{tabular}

led to a further fall in dust levels (fig 1). As there 을 were no reliable data on dust concentrations from previous years, we did not feel justified in attempting to derive a cumulative dust exposure for each worker; so the number of years spent in a particular job was accepted as the best available measure of previous exposure.

The methods of extracting kaolin in the southern United States differ from those used in the St Austell pits of Cornwall. There the clay is obtained by washing the wall of the open cast pit with a high

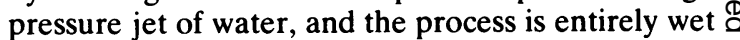
until after the kaolin slurry has been dried in kilns. $\overrightarrow{\overrightarrow{0}}$ Thereafter milling, bagging, and loading slabs of $\exists$ kaolin produce considerable amounts of kaolin dust. Some 20 years ago in the Cornish china clay industry half or more of the powdered kaolin that was generated was in the form of particles $1 \mu \mathrm{m}$ in size.

The radiological manifestations of kaolin $\stackrel{x}{x}$ pneumoconiosis, like those of most other $\frac{0}{7}$ pneumoconioses, appear to be related to the amount of dust present in the lungs and to the duration of exposure.467 Five of the 65 kaolin workers we studied had radiographic evidence of $\frac{9}{9}$ pneumoconiosis, a prevalence of $7.7 \%$. This preval- $\rightarrow$ ence rate of kaolin pneumoconiosis is similar to the $9 \%$ of other studies. ${ }^{67}$ In an earlier study, Edenfield $\bar{N}$ reported a prevalence rate of only $3.7 \%$ in $1130^{\circ}$ kaolin workers. ${ }^{4}$ This difference in the rates may be $\tilde{O}$ due to a different selection of populations under $\mathrm{N}^{\mathrm{N}}$ study . Edenfield's report probably included workers employed in the manufacture of various end pro-e ducts, whereas our study was limited to workers in mining and processing.

The values for FVC, $\mathrm{FEV}_{1}$, and $\mathrm{FEV}_{1} / \mathrm{FVC}$ were not significantly different between the subgroups in

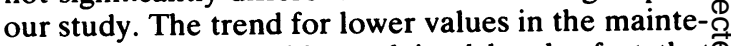
nance men is probably explained by the fact that $\stackrel{\square}{\propto}$ some had previously worked in the processing areao and had also been employed for a relatively longer 
time. Although the workers in the processing area were exposed to the highest dust concentrations, their mean spirometric values were no different from those employed elsewhere. Many of them, however, had been exposed for a relatively short time. Among those employed in the processing area, increasing duration of exposure had an effect on ventilatory capacity, leading to slight restrictive impairment. Rawlings et al $^{7}$ did not find a difference in $F E V_{1} / F V C$ ratio in workers with various categories of kaolin pneumoconiosis, but the FVC was lower in their men with simple pneumoconiosis than in those without pneumoconiosis. They did not measure lung volumes or blood gases in their study. Recently Oldham has described his findings in a large group of Cornish china clay workers. He was able to show that increasing category of pneumoconiosis had an effect on vital capacity that was independent of smoking. ${ }^{17}$

We believe that this is the first study to determine lung volumes and arterial blood gas tensions in workers with kaolin pneumoconiosis. Body plethysmographic studies confirmed the mild restrictive impairment in those with pneumoconiosis. Lung volumes were not, however, determined in workers who did not have pneumoconiosis. No correlation was found between the radiographic degree of pneumoconiosis and the reduction in lung volumes, but this is hardly surprising given the small number of subjects with radiographic evidence of the condition. Nevertheless, there is reason to believe that simple kaolinosis, like simple silicosis, is likely to lead to a minimal increase in lung stiffness. ${ }^{18}$ The minimal effect on lung function is best explained by the fact that the nodules seen in kaolinosis are separated from each other by normal functioning alveoli.

The results of arterial blood gas analyses in five workers with kaolin pneumoconiosis are difficult to interpret. The only worker with complicated pneumoconiosis had a normal alveolo-arterial oxygen gradient at rest. Since all five workers with pneumoconiosis were cigarette smokers, it is difficult to separate the contributions of smoking and pneumoconiosis to the blood gas abnormalities.

Cigarette smoking has been thought to delay dust clearance and thus increase the incidence of dust related pneumoconiosis. ${ }^{19}$ Although all five of the workers with radiological evidence of pneumoconiosis were cigarette smokers, the small number of workers in our study does not permit further comment; Rawlings et al, however, did not find any correlation between cigarette smoking and the presence of pneumoconiosis.?

\section{References}

' Middleton EL. Industrial pulmonary disease due to the inhalation of dust. Lancet 1936;ii:59-64.

${ }^{2}$ Lynch KM, McIver FA. Pneumoconiosis from exposure to kaolin dust: kaolinosis. Am J Pathol 1954;30: 1117-27.

${ }^{3}$ Hale LW, Gough J, King EJ, Nagelschmidt G. Pneumoconiosis of kaolin workers. $\mathrm{Br} J$ Ind Med 1956;13:251-9.

${ }^{4}$ Edenfield RW. A clinical and roentgenological study of kaolin workers. Arch Environ Health 1960;5:28-39.

${ }^{5}$ Warraki S, Herant Y. Pneumoconiosis in china-clay workers. Br J Ind Med 1963;20:226-30.

${ }^{6}$ Sheers G. Prevalence of pneumoconiosis in Cornish kaolin workers. Br J Ind Med 1964;21:218-25.

${ }^{7}$ Rawlings W, Kennedy T, Menkes H, Morgan R. Pulmonary functions and respiratory symptoms in a population of Georgia kaolin workers. Am Rev Respir Dis 1983;127:215-20.

${ }^{8}$ International Labour Office: Guidelines of the use of ILO international classification of radiographs of pneumoconiosis. Revised ed. Geneva: International Labour Office, 1980.

${ }^{9}$ American Thoracic Society. Statement of Snowbird workshop on standardization of spirometry. Am Rev Respir Dis 1979;119:831-8.

${ }^{10}$ Dubois AB, Botelho SY, Bedell GN, Marshall R, Comroe $\mathrm{JH}$. A rapid plethysmographic method for measuring thoracic gas volume. A comparison with a nitrogen washout method for measuring functional residual capacity in normal subjects. J Clin Invest 1956; 35:322-6.

$"$ Morris JF, Koski A, Breese JD. Normal values and evaluation of forced end expiratory flow. Am Rev Respir Dis 1975;111:755-62.

12 Goldman HI, Becklake MR. Respiratory function tests: normal values at median altitudes and the prediction of normal results. Am Rev Tuberc 1959;79:457-67.

${ }^{13}$ Lapp NL, Amandus HE, Hall R, Morgan WKC. Lung volumes and flow rates in black and white subjects. Thorax 1974;29:185-8.

${ }^{14}$ American Conference of Government Industrial Hygienists. Documentation of threshold values. 4th ed. Cincinnati: American Conference of Government Industrial Hygienists, 1980:312.

${ }^{15}$ Lesser M, Zia M, Kilburn K. Silicosis in kaolin workers and firebrick makers. South Med J 1978;71:1242-6.

${ }^{16}$ Georgia Institute of Technology. Dust sampling report to Thiele Kaolin Company. Georgia Institute of Technology, 5 February 1967.

${ }^{17}$ Oldham P. Pneumoconiosis in Cornish china clay workers. Br J Ind Med 1983;40:131-7.

${ }^{18}$ Teculescu DB, Stanescu DC, Pilat L. Pulmonary mechanics in silicosis. Arch Environ Health 1967; 14:461-8.

${ }^{19}$ Cohen DF, Arai SF, Brain JD. Smoking impairs longterm dust clearance from the lung. Science 1979;204:514-7. 